\title{
Typical Computed Tomographic Images and Operation for Grade IV Pancreatic Injury
}

\author{
Chan Yong Park, Wu Seong Kang \\ Department of Trauma Surgery, Wonkwang University, Jeonbuk, Korea
}

The American Association for the Surgery of Trauma (AAST) defines grade IV pancreatic injury as proximal transection to the right of the superior mesenteric vein or parenchymal injury involving the ampulla. However, there are rare reports of computed tomographic images that match the surgical photographs of grade IV injury. We report computed tomographic and operation images of a typical grade IV pancreatic injury in a 43-year-old woman with a proximal transection of the pancreas after a traffic accident.

(Trauma Image Proced 2019(1):3-5)

Key Words: Grade IV pancreatic injury, Proximal transection, Superior mesenteric vein, Images

\section{CASE}

A 43-year-old woman who had been in a traffic accident was referred to our emergency department from another hospital after a driver traffic accident. Her initial vital signs were unstable: blood pressure, $75 / 58 \mathrm{~mm} \mathrm{Hg}$; pulse rate, 95 beats/min; respiration rate, 18 breaths $/ \mathrm{min}$; body temperature, $36.8^{\circ} \mathrm{C}$; and oxygen saturation, $98 \%$. Abdominal computed tomography (CT) performed at another hospital revealed complete transection of the pancreas to the right of the superior mesenteric vein (Fig. 1.). Injury severity score of the patient was 57. Emergency surgery was performed, and pancreatic transection was observed (Fig. 2.). The splenic artery and vein were ligated at their proximal portions (Fig. 3.), and subtotal pancreatectomy was performed (Fig. 4.). After ligation of the main pancreatic duct in the remnant pancreas, the pancreatic stump was closed by fish-mouth interrupted sutures. The initial serum amylase and lipase levels were 104 and $275 \mathrm{IU} / \mathrm{L}$, respectively, and their levels were highest (797 and $671 \mathrm{IU} / \mathrm{L}$, respectively) on day 3 (Fig. 5.). A pancreatic pseudocyst was developed during follow-up period and succesfully treated by percutaneous drainage.

\section{DISCUSSION}

Pancreatic injuries caused by trauma are rare but associated with significant morbidity and mortality. Heuer et al. (1) reported the results of pancreatic injury through the Trauma Register of the German Society of Trauma Surgery (TRDGU) (1993-2009). In this study mortality was $30.0 \%$ for grade IV pancreatic injury. Mohseni et al. (2) reported mortality of penetrating grade IV pancreatic injuries through trauma quality improvement (TQIP) databank analysis. In this study,

Received: March 2, 2019 Revised: April 23, 2019 Accepted: May 8, 2019

Correspondence to: Chan Yong Park, MD, Department of Trauma Surgery, Wonkwang University Hospital, Jeonbuk, Korea

Tel: 82-63-859-2602, Fax: 82-63-859-2029, E-mail: wkafyddl@hanmail.net

Copyright (c) 2019 Korean Association for Research, Procedures and Education on Trauma. All rights reserved.

@This is an open-access article distributed under the terms of the Creative Commons Attribution Non-Commercial License (http://creativecommons.org/

licenses/by-nc/4.0) which permits unrestricted noncommercial use, distribution, and reproduction in any medium, provided the original work is properly cited 


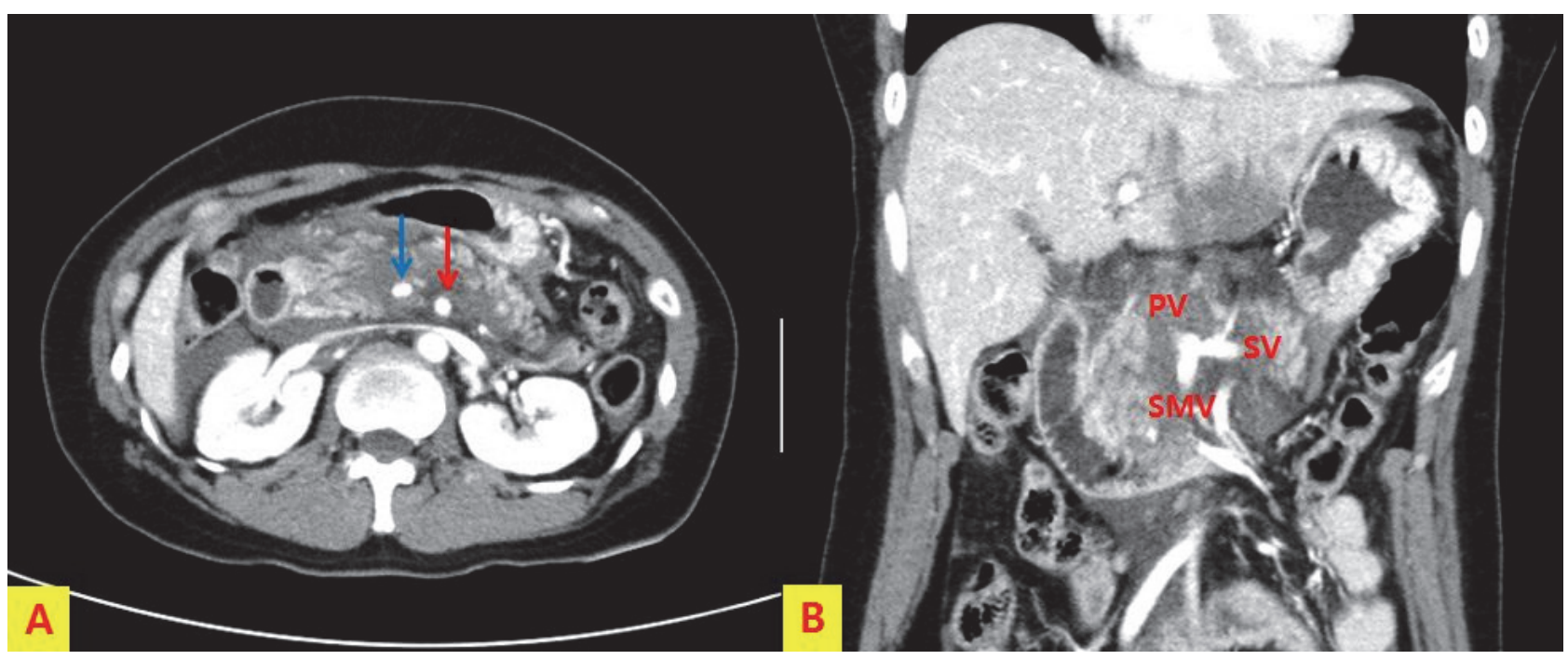

Fig. 1. Abdominal CT performed at another hospital revealed complete transection of the pancreas to the right of the superior mesenteric vein (blue arrow: superior mesenteric vein, red arrow: superior mesenteric vein, PV: portal vein, SV; splenic vein, SMV; superior menseteric vein).

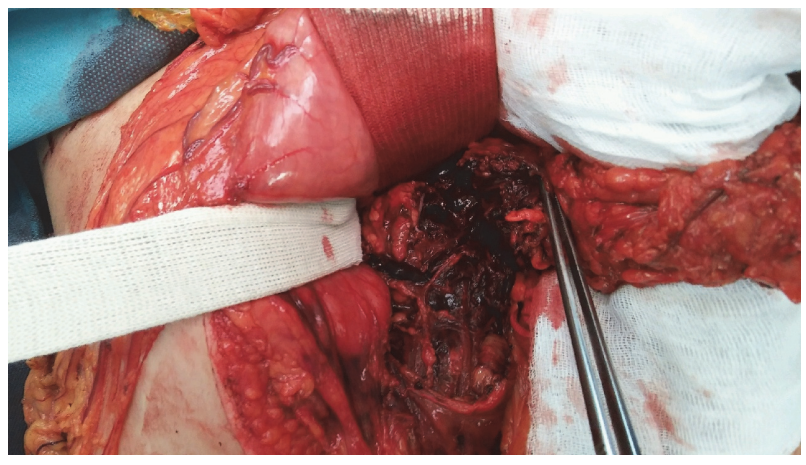

Fig. 2. Emergency surgery was performed and complete transection of the proximal portion of the pancreas was observed.

mortality was $24.0 \%$ in the resection group and $27.1 \%$ in the non-resection group $(\mathrm{p}=0.68)$. However, there are reports that surgical management has better prognosis for grade IV pancreatic injuries confirmed by CT or surgery $(3,4)$.

American Association for the Surgery of Trauma (AAST) defines grade IV pancreatic injury as proximal transection to the right of the superior mesenteric vein (SMV) or parenchymal injury involving the ampulla. However, there are rare reports of CT images matching the surgeries. Therefore, we report a case of complete transection of the pancreas to the right of the SMV after

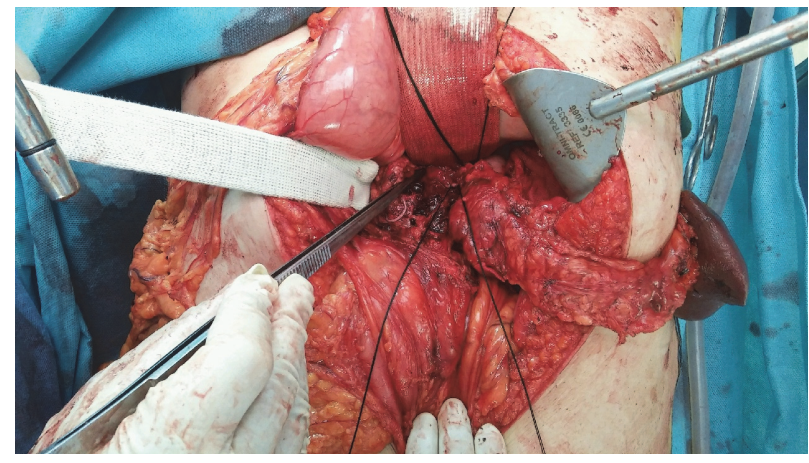

Fig. 3. A: Splenic artery was ligated at the proximal portion near celiac trunk (upper). B: Splenic vein was ligated at the proximal portion near portal vein (lower). On the left side of the ligation site, the proximal portion of the completely transected pancreas and the exposed main pancreatic duct are observed.

blunt injury with typical images including surgical findings.

\section{Conflict of Interest Statement}

None of authors has a conflict of interest

\section{REFERENCE}

1. Heuer M, Hussmann B, Lefering R, Taeger G, Kaiser GM, Paul A, et al. Pancreatic injury in 284 patients with severe abdominal trauma: outcome, course, and treatment 


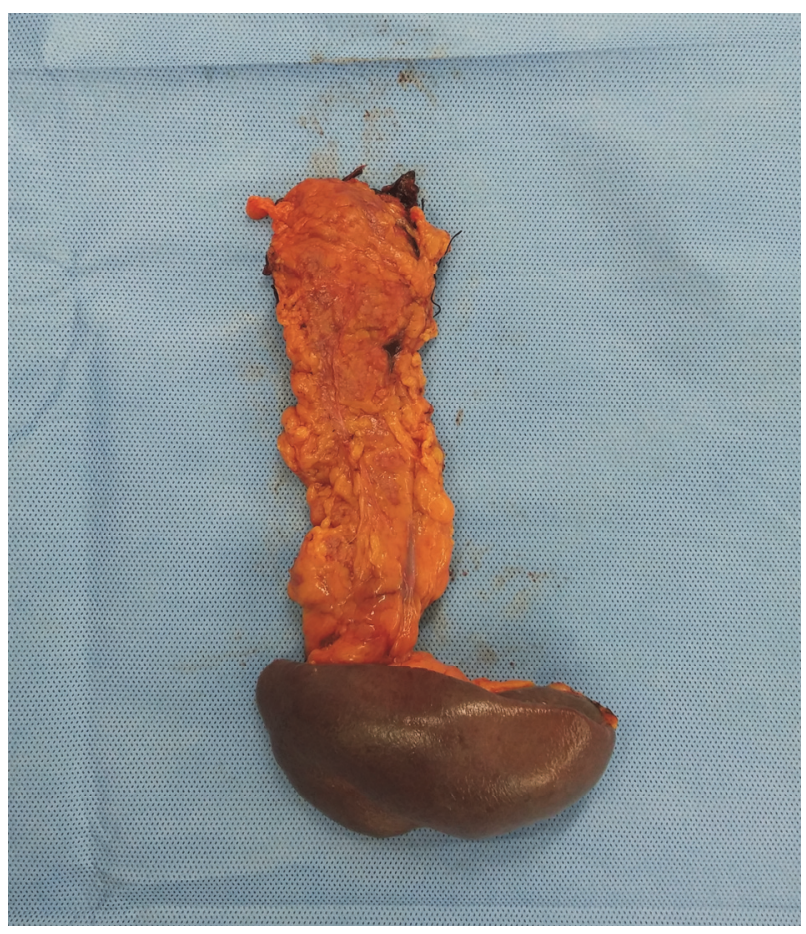

Fig. 4. There is specimen after subtotal pancreatectomy.

algorithm. Langenbecks Arch Surg 2011;396(7):1067-76.

2. Mohseni S, Holzmacher J, Sjolin G, Ahl R, Sarani B. Outcomes after resection versus non-resection management

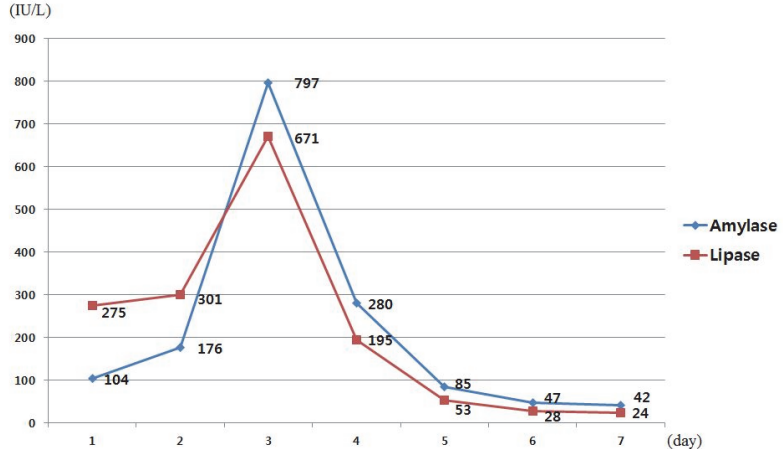

Fig. 5. The initial amylase/lipase was 104/275 IU/L and the highest at $797 / 671 \mathrm{IU} / \mathrm{L}$ on the $3^{\text {rd }}$ day.

of penetrating grade III and IV pancreatic injury: A trauma quality improvement (TQIP) databank analysis. Injury 2018;49(1):27-32.

3. Ho VP, Patel NJ, Bokhari F, Madbak FG, Hambley JE, Yon JR, et al. Management of adult pancreatic injuries: A practice management guideline from the Eastern Association for the Surgery of Trauma. J Trauma Acute Care Surg 2017;82(1):185-99.

4. Singh RP, Mahajan A, Selhi JS, Garg N, Chahal H, Bajwa M. Management and Outcome of Patients with Pancreatic Trauma. Niger J Surg 2017;23(1):11-4. 